\title{
THE GENETIC BASIS OF AN INVARIANT CHARACTER IN WHEAT
}

\author{
O. H. FRANKEL, B. SHINEBERG* and ANNE MUNDAY \\ Division of Plant Industry, CSIRO, Canberro, Australia
}

Received 11.xii.68

\section{INTRODUGTION}

WADDington (1957) pointed out that the fundamental processes of development in a higher organism are characterised by a marked invariance of their end-state. He explained this stability by assuming that developmental processes are canalised or buffered against environmental and genetic factors tending to deflect them from their normal pathway. The degree to which a developmental pathway is canalised is under the control of genes which stabilise the pathway against the effect of combinations of genes tending to produce variability.

In a study of crossveinless in Drosophila melanogaster, Waddington (1953) demonstrated cryptic genetic variance under temperature stress during a sensitive stage of the life-cycle. He selected populations which showed an increased response to the stress and ultimately manifested the defect under normal conditions. In a series of studies on scutellar bristle number in D. melanogaster (Rendel 1959, et seq.) and on facial vibrissae in mice (Dun and Fraser, 1958, et seq.), mutant genes have been used to reveal genetic variation which can be utilised by selection but is not expressed in the normal animal.

A study of basal fertility in common wheat, Triticum aestivum ssp. vulgare, where the normal phenotype is shown to be invariant despite environmental and genetic variation, has revealed a number of striking analogies with these systems.

The wheat inflorescence or head consists of two parallel rows of sessile spikelets attached to an axial rachis, and a single terminal spikelet oriented at right angles to the remainder. The pattern of floral morphology in typical vulgare wheats is as follows. Each spikelet is subtended by two sterile basal glumes; above these is a variable number of bract-like lemmas which enclose fully competent flowers, and at the apex there is a number of bracts and florets which fail to develop. The invariance in the pattern of flower development in base fertile wheats resides in the fact that fully developed flowers, competent to produce seed, are laid down in the axil of the lowest lemma and in those of the succeeding ones. The zone of floral competance may shift in one or the other of two directions; either downwards to the normally sterile glumes or upwards to the second or succeeding lernmas. While the first alternative is found in some wheats and has been induced minimally in our vulgare stocks, the second is characteristic of the mutants and selections used in the present study. Stocks where floral development is displaced upwards from the level of the first lemma are referred to as base sterile.

In a preliminary study, Frankel and Fraser (1948) showed that basal

* Present address: Botany Department, School of General Studies, Australian National University, Canberra, Australia.

This paper is dedicated to Professor Th. Dobzhansky in commemoration of his 70 th birthday, January 251970. 
fertility is closely associated with the syndrome of vulgare characters-soft glumes, tough rachis and short internodes-which is under the control of the $Q$ locus on the long arm of chromosome 5A. Speltoidy which stems from a deletion of the $Q$ locus (Huskins, 1946) is a necessary, though not sufficient, condition for the occurrence of basal sterility. An analysis of these speltoids revealed the presence of genetic variability which is normally suppressed by the $Q$ locus.

In the present paper we examine the nature of the genetic processes affecting basal fertility and attempt to specify their role in buffering the expression of this character against variability due to environmental and genetic factors. Evolutionary and physiological aspects of the problem will be reported elsewhere.

TABLE 1

The Speltoid stocks

\begin{tabular}{|c|c|c|c|c|}
\hline Code & Parentage & Origin & $\begin{array}{c}\text { Locality and year } \\
\text { of origin }\end{array}$ & $\begin{array}{l}\text { Sterile base } \\
\text { score }\end{array}$ \\
\hline$S t_{\mathrm{FF}}$ & $S t_{\mathrm{F}} \times S t_{2}$ & Selection to $F_{5}$ & Canberra, 1962 & $0 \cdot 000 \pm 0 \cdot 000$ \\
\hline$S t_{\mathrm{F}}$ & Victor $\times S t_{1}$ & Selection to $F_{3}$ & Lincoln, N.Z., 1934 & $0.075 \pm 0.014$ \\
\hline$S t_{1 \mathrm{~A}}$ & Fife-Tuscan & Mutation & Lincoln, N.Z., 1952 & $0.386 \pm 0.074$ \\
\hline$S t_{1}$ & Yeoman & Mutation & Lincoln, N.Z., 1930 & $0.964 \pm 0.009$ \\
\hline$S t_{2}$ & $\begin{array}{l}\text { Breeding material } \\
\text { (details unknown) }\end{array}$ & Mutation & $\begin{array}{l}\text { Waite Agricultural } \\
\text { Research Institute, } \\
\text { Adelaide, about } \\
1945\end{array}$ & $1 \cdot 414 \pm 0 \cdot 025$ \\
\hline
\end{tabular}

\section{Material AND methods}

(i) The basal-sterile mutants and their derivatives

Three independent mutants, each a homozygous speltoid, provided the original material. Other types were obtained from crosses between some of the mutants, or between mutants and normal vulgare wheats. They are briefly described in table 1. All experimental plantings used in the analysis reported in this paper were made in the open in Canberra. Determinations of flower development were made on the largest head of a plant.

\section{(ii) The nature and identification of basal sterility}

In a detailed study of the development of normal and defective florets in base-sterile mutants, Barnard (1955b) found three well-defined types of defects which he termed imperfect, rudimentary or empty. Imperfect florets are normal except that the anterior stamen is deformed or missing; such florets are often functional. In rudimentary flowers the floral organs are deformed and often fused. Imperfect and rudimentary flowers are normally found in "transitional" positions within a spikelet, viz., in the florets immediately below the first normal one. Empty flowers lack flowering organs altogether. In all data used in this paper the criterion of basal sterility is a twisted, reduced or missing palea, which in Barnard's observations was as a rule associated with a drastic deformation or absence of flowering organs, and which we have found to be closely correlated with the failure to set seed. However, since in normal wheat seed-set rarely reaches 100 per cent., a reduced or missing palea was found to be a more exact 
criterion of basal sterility than a failure to set seed which was used prior to 1957.

The upward shift of the zone of floral competence that occurs in the spikelets of base sterile plants tends to be compensated for by the full development of upper florets which normally remain immature in base fertile plants. This is illustrated in fig. 1, in which a comparison is made of the means of spikelet basal sterility and grain set of speltoid lines for the year 1967.

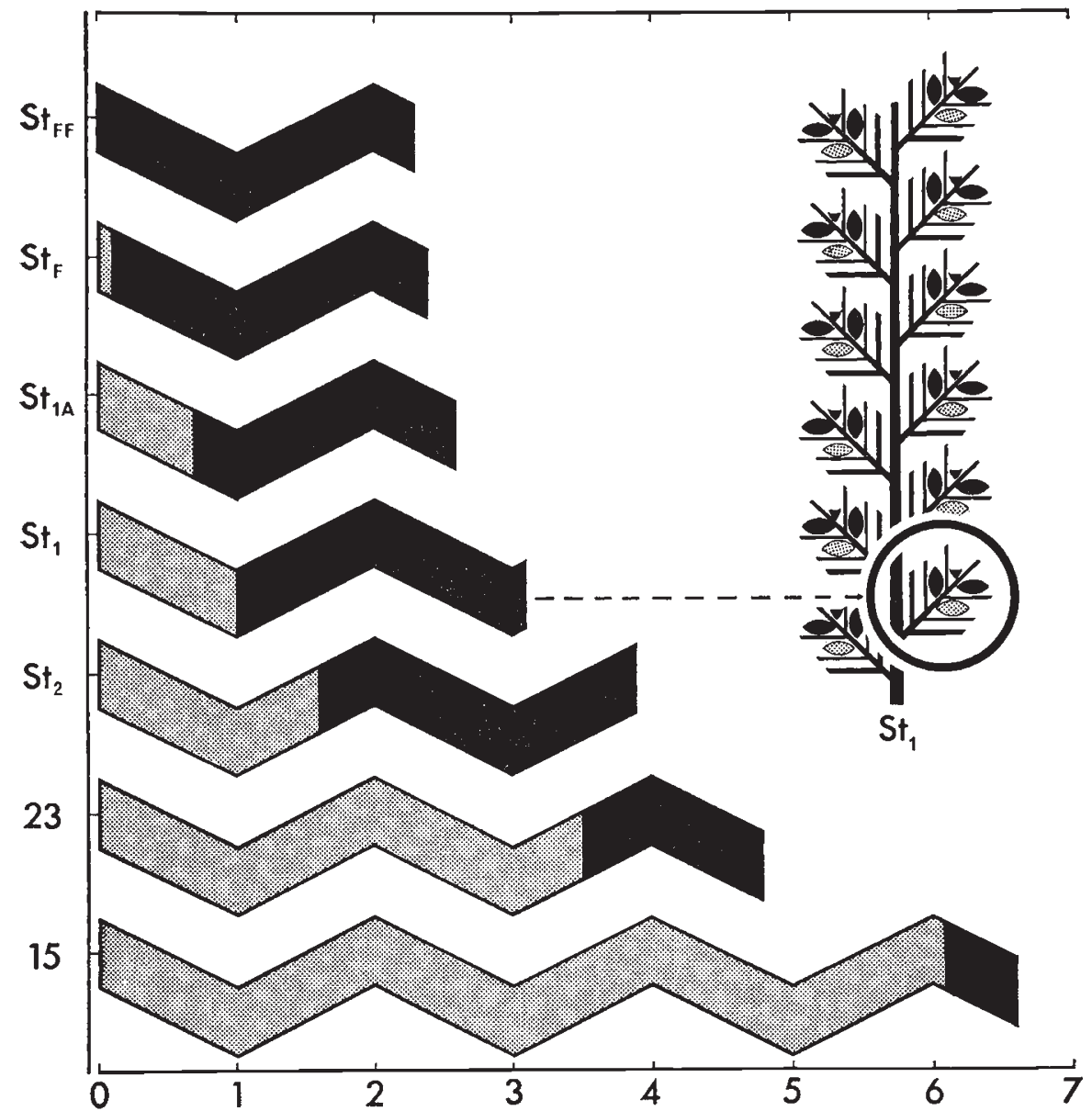

FIG. 1.-Estimates from 1967 plants of average numbers of base sterile florets (grey) and fully formed grains (black) in the spikelets of speltoid lines. The sterile base scale is shown on the horizontal axis. The inset figure illustrates the typical positioning of grains in $S t_{1}$. Each spikelet is subtended by two empty glumes. Grains are formed in the axils of lemmas.

(iii) The sterile base index

The incidence of basal sterility has been assessed by the mean number of defective basal florets per spikelet in a head. This measure is referred to as the sterile base index.

By using this index it is possible to transform a series of discrete observations-each head consisting of spikelets with $0,1,2 \ldots$ defects-into a 


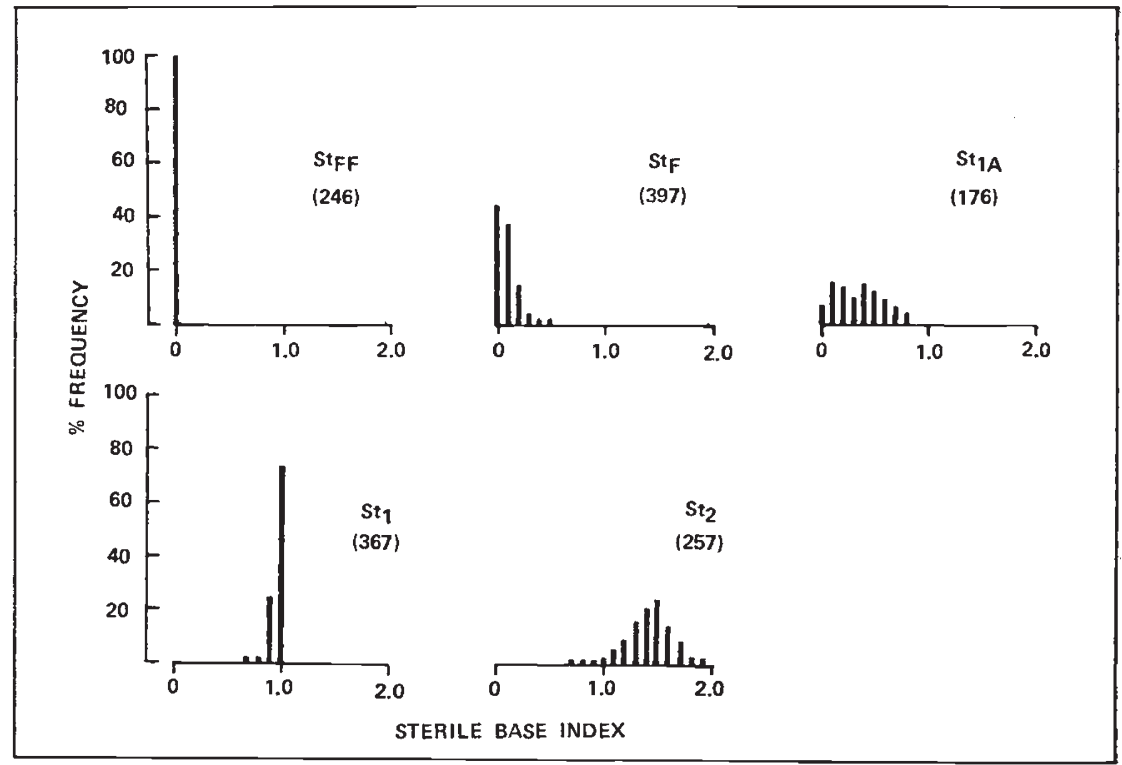

Fig. 2.-Pooled frequency distributions of speltoid parents from the years 1957-1967. The numbers of plants grown are shown in brackets on each distribution.

TABLE 2

Means and standard deviations of speltoid parents

$\begin{array}{lccccc} & S t_{\mathrm{FF}} & S t_{\mathrm{F}} & S t_{1 \mathrm{~A}} & S t_{1} & S t_{2} \\ \text { Grand mean } & 0 \cdot 000 & 0.075 & 0.386 & 0.964 & 1.414 \\ \begin{array}{c}\text { Mean standard } \\ \text { deviation }\end{array} & 0.000 & 0.084 & 0.189 & 0.043 & 0.199 \\ \begin{array}{c}\text { Standard error, } \\ \text { grand mean }\end{array} & 0.000 & 0.014 & 0.074 & 0.009 & 0.025 \\ \quad & & & & & \end{array}$

\section{Year means}

$\begin{array}{lccccc}1957 & - & 0.051 & 0.541 & 0.945 & 1.398 \\ 1960 & - & 0.168 & - & 0.923 & 1.609 \\ 1961 & - & 0.051 & - & 0.944 & 1.415 \\ 1962 & - & 0.051 & 0.361 & 0.978 & - \\ 1963 & 0.000 & 0.039 & - & 0.982 & 1.471 \\ 1964 & 0.000 & 0.088 & 0.718 & 0.925 & 1.358 \\ 1965 & 0.000 & 0.050 & 0.127 & 0.987 & 1.381 \\ 1966 & 0.000 & 0.117 & 0.483 & 0.987 & 1.373 \\ 1967 & 0.000 & 0.122 & 0.294 & 0.969 & 1.443\end{array}$

\section{Year standard deviations}

$\begin{array}{lccccc}1957 & - & 0 \cdot 067 & 0 \cdot 157 & 0.040 & 0 \cdot 151 \\ 1960 & - & 0 \cdot 117 & - & 0.055 & 0 \cdot 191 \\ 1961 & - & 0 \cdot 062 & - & 0.042 & 0 \cdot 144 \\ 1962 & - & 0.080 & 0 \cdot 197 & 0 \cdot 033 & - \\ 1963 & 0 \cdot 000 & 0 \cdot 063 & - & 0 \cdot 024 & 0.319 \\ 1964 & 0 \cdot 000 & 0 \cdot 105 & 0 \cdot 164 & 0 \cdot 067 & 0 \cdot 180 \\ 1965 & 0 \cdot 000 & 0 \cdot 058 & 0 \cdot 129 & 0 \cdot 034 & 0 \cdot 256 \\ 1966 & 0 \cdot 000 & 0 \cdot 107 & 0.243 & 0 \cdot 038 & 0 \cdot 145 \\ 1967 & 0 \cdot 000 & 0 \cdot 074 & 0 \cdot 165 & 0 \cdot 047 & 0 \cdot 126\end{array}$


single, continuous variable expressing the average amount of basal sterility which occurs in a head. Although convenient, the sterile base scale has two obvious shortcomings. It does not account for either the variance of basal sterility within the head, or of the pattern of incidence along its axis. However, in both these respects there is a good deal of regularity, and, where significant deviations occur, they are noted in the analysis.

\section{THE NATURE OF VARIATION IN BASE STERILE POPULATIONS}

The stability of sterile base lines has been estimated from the magnitude of the standard deviations of individual progenies and the yearly fluctuations of their means. These tend to zero in highly buffered lines.

The yearly means and standard deviations of speltoid parents are listed in table 2. Frequency distributions of scores pooled from different years are presented in fig. 2. The stability of the lines $S t_{\mathrm{FF}}, S t_{\mathrm{F}}$ and $S t_{1}$ compared

TABLE 3

Analysis of variance for parent speltoid stocks $\dagger$

\begin{tabular}{|c|c|c|c|}
\hline$S t_{\mathrm{F}}$ Source & d.f. & Mean square & $F$ ratio \\
\hline $\begin{array}{l}\text { Between years } \\
\text { Within years }\end{array}$ & $\begin{array}{r}8 \\
388\end{array}$ & $\begin{array}{l}0.069267 \\
0.006986\end{array}$ & $9 \cdot 915^{* * *}$ \\
\hline$S t_{1 \mathrm{~A}}$ & & & \\
\hline $\begin{array}{l}\text { Between years } \\
\text { Within years }\end{array}$ & $\begin{array}{r}5 \\
170\end{array}$ & $\begin{array}{l}0.930140 \\
0.035809\end{array}$ & $\begin{array}{c}25 \cdot 975^{* * *} \\
-\end{array}$ \\
\hline$S t_{1}$ & & & \\
\hline $\begin{array}{l}\text { Between years } \\
\text { Within years }\end{array}$ & $\begin{array}{r}8 \\
358\end{array}$ & $\begin{array}{l}0.025418 \\
0.001840\end{array}$ & $\begin{array}{c}13 \cdot 812^{* * *} \\
-\end{array}$ \\
\hline$S t_{2}$ & & & \\
\hline $\begin{array}{l}\text { Between years } \\
\text { Within years }\end{array}$ & $\begin{array}{r}7 \\
249\end{array}$ & $\begin{array}{l}0 \cdot 162119 \\
0 \cdot 039574\end{array}$ & $\begin{array}{c}4.097 * * * \\
-\end{array}$ \\
\hline
\end{tabular}

with $S t_{1 \mathrm{~A}}$ and $S t_{2}$ is demonstrated by their low standard deviations (table 2) and, as may be seen in fig. 2, is associated with the truncation of their sterile base index distributions at the values 0 or 1 . The zero standard deviations of $S t_{\mathrm{FF}}$ progenies mark this line as completely buffered.

It is clear from table 2 that the mean values of most lines may differ considerably from year to year. That these shifts are highly significant in all lines except $S t_{\mathrm{FF}}$ is confirmed by $\mathrm{F}$ tests (table 3 ), which can justifiably be made within a line in view of the basic similarity of their standard deviations and the shape of their distributions from year to year. However, table 2 shows that the yearly fluctuations of the mean values of progenies are smaller in lines with low standard deviations.

The normal parametric statistical methods may not be used for testing differences between parents because of the dissimilarities of their distributions. There are, however, characteristic differences between parents which persist from year to year. $S t_{1 \mathrm{~A}}$ means fall around the centre of the $0-1$ range and are clearly different from populations of other parents to the right and left. 
$S t_{2}$ distributions lie in the 1-2 range and are discrete from those of other parents. The only critical overlap occurs between the lines $S t_{F}$ and $S t_{F F}$, the distributions for which are truncated at point 0 . Though the means of
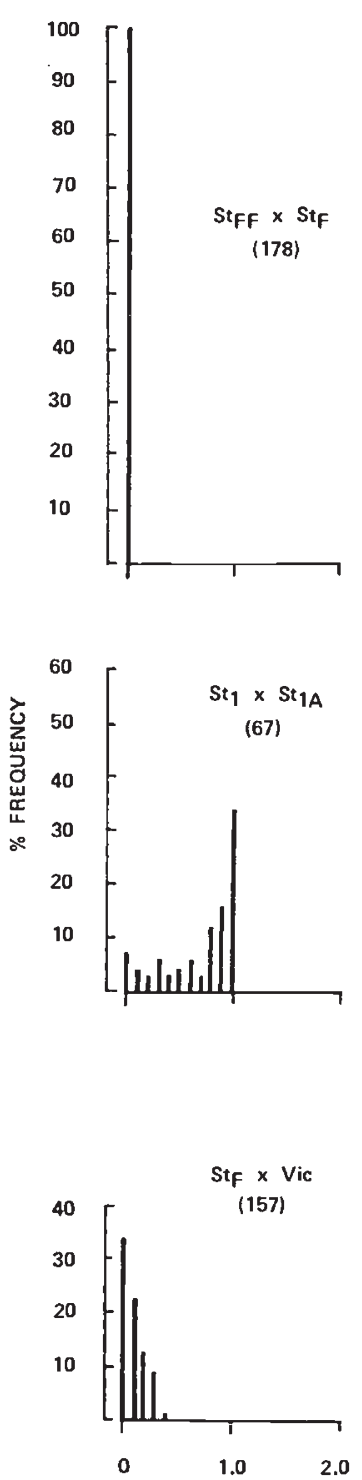
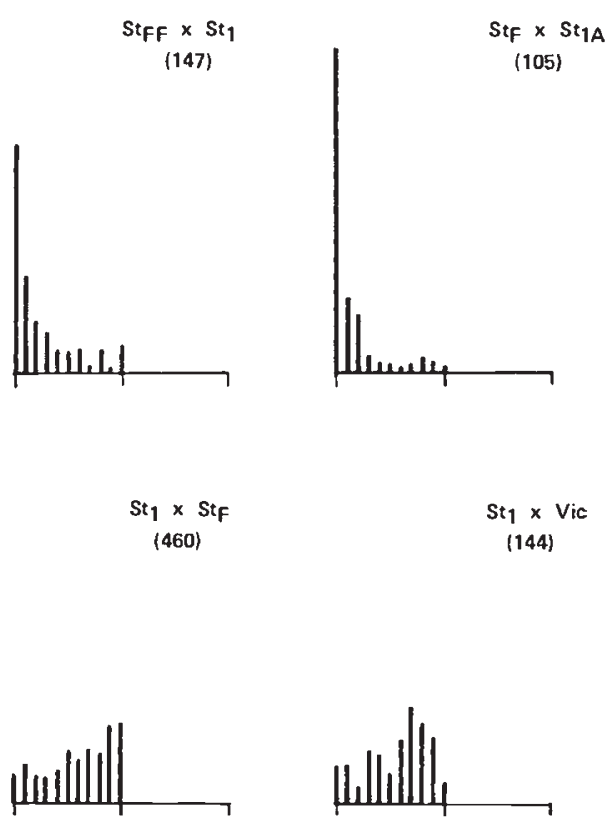

$\mathrm{St}_{1} \times \mathrm{Vic}$

(144)
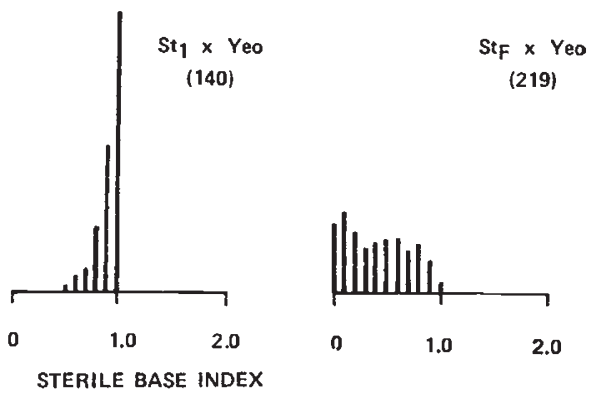

FIG. 3.-Pooled frequency distributions of $\mathrm{F}_{2}$ plants from speltoid crosses not involving $S t_{2}$. The $\mathrm{F}_{2}$ distributions of crosses of these speltoids with the Vulgares, Victor and Yeoman are also shown. The numbers of plants grown are shown in brackets on each distribution.

their distributions are very close (table 2 ), $S t_{\mathrm{FF}}$ populations are quite different from those of $S t_{\mathrm{F}}$ since they have consistently zero means and standard deviations each year. From these considerations it is clear that one is dealing with genetically distinct stocks. 
The variation of the basal sterility in speltoid lines is discontinuous at the points 0 and 1 . The discontinuity at point 0 is simply due to the fact that flower formation is normally initiated in the axil of the first lemma. At
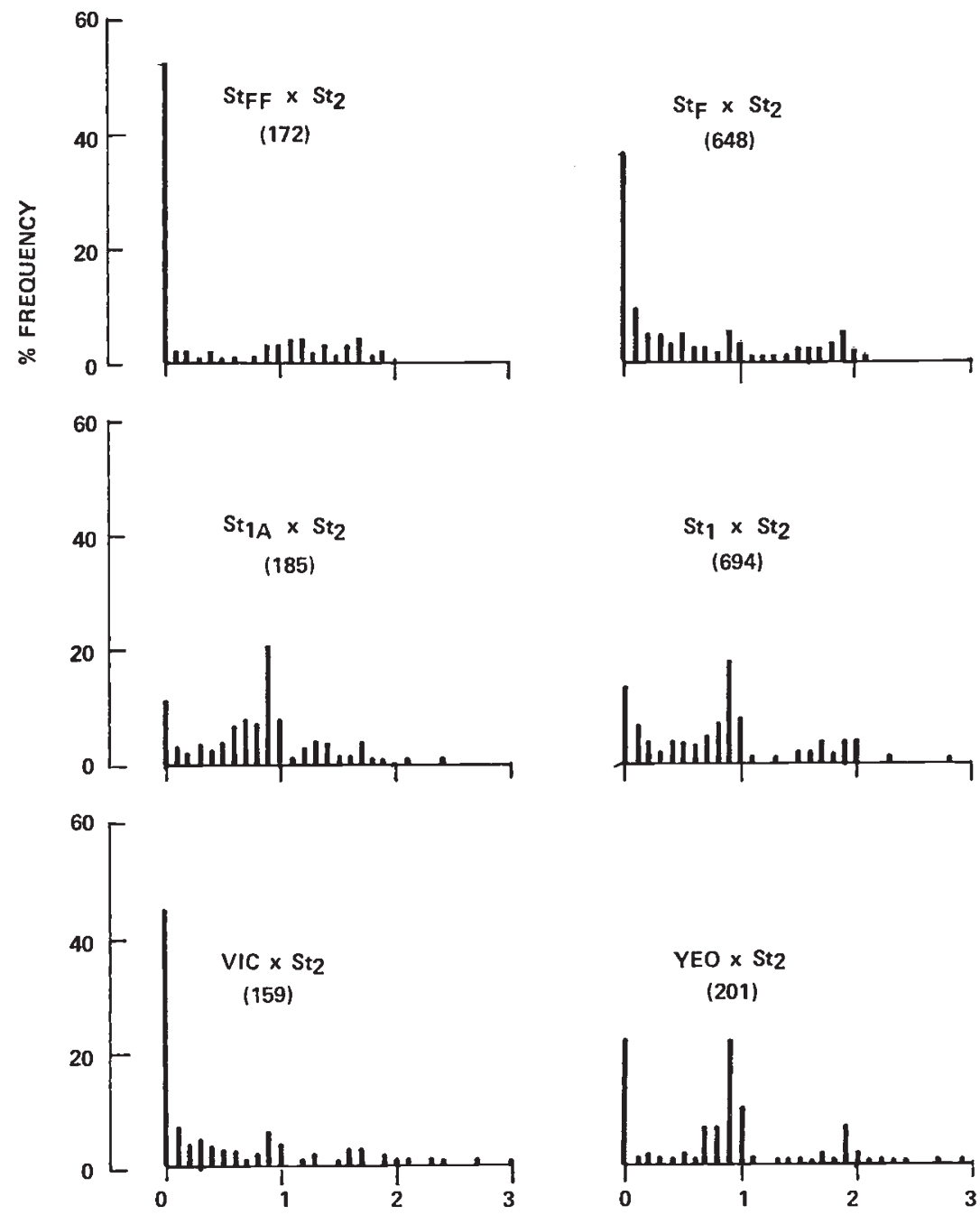

STERILE BASE INDEX

Frg. 4.- Pooled frequency distributions of $\mathrm{F}_{2}$ plants from crosses between $S t_{2}$ and other speltoids are the Vulgares, Victor and Yeoman. The numbers of plants grown are shown in brackets on each distribution.

point 1 it occurs when all first flowers are sterile. This discontinuity, unlike that at 0 , is amenable to analysis because variation on both sides of it has been readily obtained. Distributions are clearly truncated at 1 in $F_{2}$ populations from $S t_{1}$ or $r_{e o m a n}$ (fig. 3). But truncation is also evident in $\mathrm{F}_{2} \mathrm{~s}$ from $S t_{2}$ in crosses with $S t_{1}$ and $S t_{1 \mathrm{~A}}$ where the distributions show a clear break at point 1 (fig. 4). 
This discontinuity is associated with the transition from first to second flower defects. Between 0 and 1 there is a steady increase in the number of defective first flowers up to a point where all but perhaps the apical spikelet have a defective basal floret. As a rule, in lines derived from $S t_{2}$ crosses, second flower defects do not occur until this point is reached. The regularity in the accumulation of first flower defects up to point 1 is, however, not without exception. In about 2 per cent. of the $\mathrm{F}_{2} \mathrm{~s}$ from crosses with $S t_{2}$, plants with an index less than or equal to 1 are found with defective second flowers. An understanding of this condition comes from lines derived from $\mathrm{F}_{2}$ plants with an index slightly greater than 1 in $\mathrm{F}_{2} \mathrm{~s}$ of $S t_{2}$ with $S t_{1}$ and $S t_{\mathrm{F}}$ which were selected for increased fertility. Progenies from these lines retain spikelets with second flower defects in spite of the accumulation of completely base fertile spikelets. In this respect they are quite distinct from typical plants with an index less than or equal to 1 , and reflect a loss of coordination of floral differentiation along the head.

The connection between the extent of buffering in lines and their mean sterile base values emerges from the data for the speltoid parents (table 2). This was examined more completely in a series of $F_{7}$ speltoid lines selected from the crosses $\left(S t_{1} \times S t_{2}\right),\left(S t_{\mathrm{F}} \times S t_{2}\right)$ and $\left(S t_{\mathrm{F}} \times Y_{\text {eoman }}\right)$. One hundred and ten of these, together with parents, were allocated at random to field rows, each containing 22 plants. In fig. $5 a$, the standard deviations have been plotted against progeny mean sterile base scores over the range 0-9. Since the parents of the test plants were selected from $F_{6}$ progenies which had failed to segregate in spite of disruptive selection, the test plants were probably highly homozygous though this cannot be determined because of the inherent developmental instability of the highly sterile lines. It is clear that the relation between progeny standard deviations and mean sterile base scores is independent of cross or parent which are shown individually. As with the parents, there is a tendency for the standard deviation of progenies lying in the 0-1 range to go to zero as their means approach the extremes of the range. Beyond point 1 there is a rise in the standard deviation which is approximately proportional to that of their mean sterile base score. This indicates that with increasing basal sterility, populations become steadily more unstable in their manifestation of the character. Another aspect of this discontinuity is shown in fig. $5 b$. Here a plot similar to fig. $5 a$ has been made for the sterile base range $0 \cdot 7-1 \cdot 1$. It includes $F_{6}$ progenies selected for high basal fertility from $\left(S t_{1} \times S t_{2}\right)$ and $\left(S t_{\mathrm{F}} \times S t_{2}\right)$ plants with scores slightly greater than 1. For comparison, the plots of corresponding $F_{6}$ progenies of the $\left(S t_{\mathrm{F}} \times Y_{e o m a n}\right)$ cross, which are not affected by second flower defects, are included. The large standard deviations of the high basal fertility selections from the $S t_{2}$ crosses are in marked contrast to those of the $\left(S t_{\mathrm{F}} \times Y_{\text {eoman }}\right)$ lines with similar scores.

In view of the discontinuity at point 1 , it might be asked whether discontinuities occur at other points corresponding to integral values on the sterile base scale. For example, should one expect a discontinuity at point 2, with all second florets defective and the third florets completely fertile? In spite of the fact that in passing from 1 to 2 on our scale (and to a lesser extent from 2 to 3 ), there is a considerable build-up of second flower defects before third florets begin to be affected, there is no evidence of any discontinuity corresponding to that at point 1 .

Two main factors may be involved in blurring such an underlying 


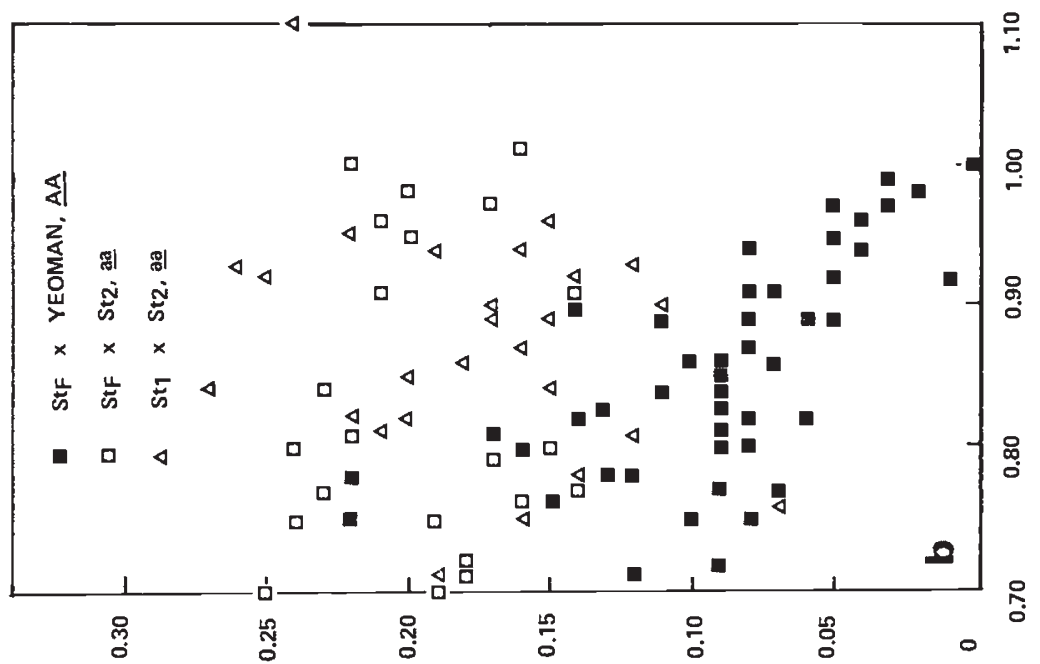

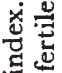

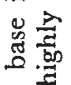

运

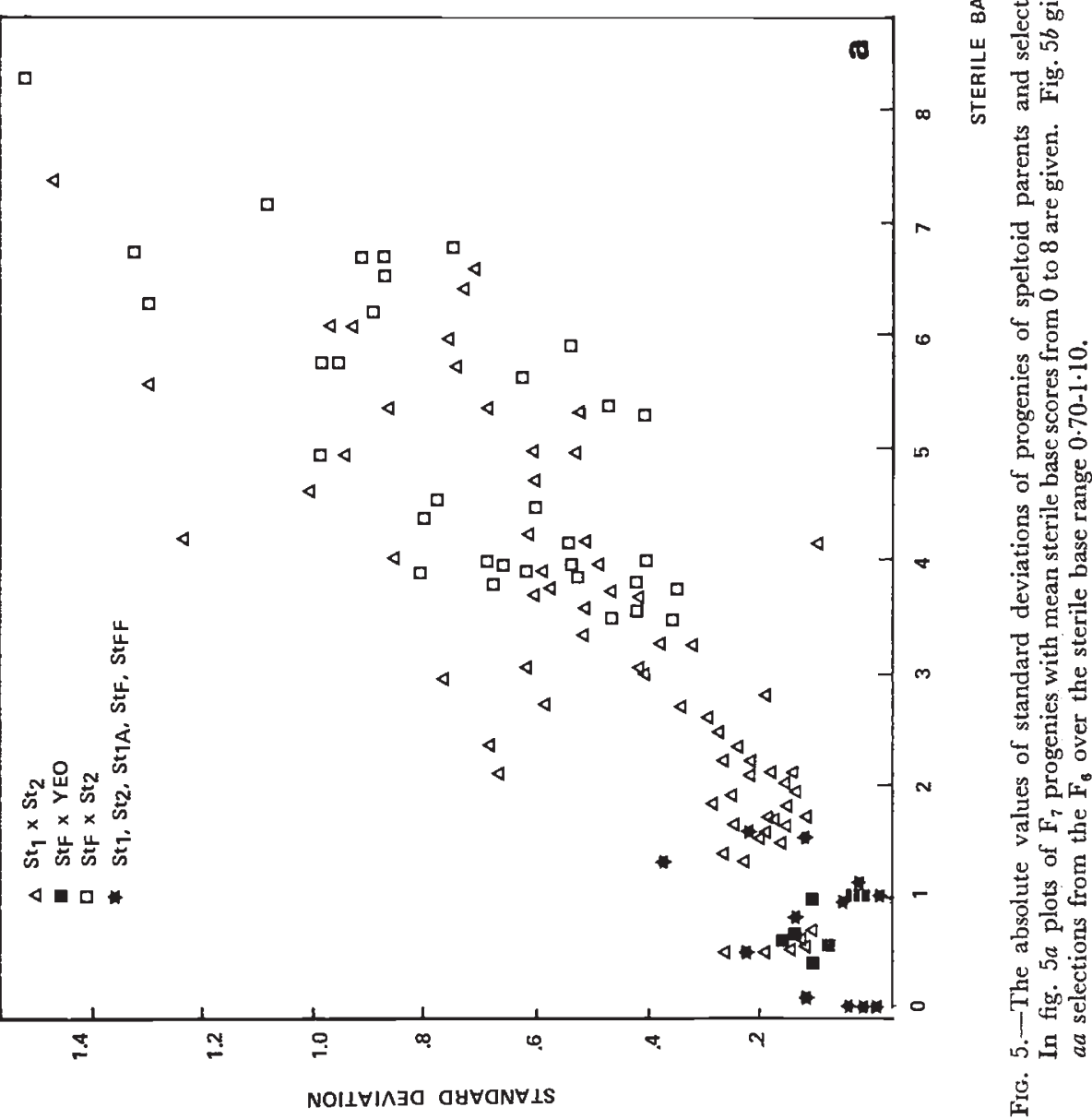


discontinuity: firstly, the increasing instability of populations of high sterile base index and, secondly, a relaxation of the normally strict within-head regulation of spikelet differentiation in the more sterile lines.

\section{Genetic Systems AfFegting BAsAl Sterility}

(i) The $\mathrm{Q}$ factor

Two questions are relevant here: firstly, is buffering against basal sterility complete in normal wheat; and, secondly, what is the effect of reducing the dosage of $Q$ or of incorporating some of the genetic background of base-sterile mutants in the presence of one or two doses of $Q$ ?

As to the first question, no base-sterile defects have been found in many hundreds of vulgare plants, either in parent lines such as Victor and reoman or vulgare-type segregates from crosses with speltoid lines, when these have been examined in a mature state. An abnormality which is not uncommon in some varieties, the absence or malformation of the anterior stamen, does not impair normal fertility. This developmental stability prevails over a great range of environments - controlled as well as natural - to which wheats have been exposed. High temperatures or low soil fertility may affect the development of entire spikelets, or the upper florets within the spikelet, but not the development of basal florets alone.

Answers to the second question come from an analysis of the heterozygous speltoid segregates from crosses of Victor and Yeoman with the speltoid lines, $S t_{\mathrm{F}}$ and $S t_{1}$. In these there was no indication of a breakdown in the buffering against basal sterility. The protection that $Q$ provides against basal sterility is thus independent of dosage and of the genetic background of these speltoids.

\section{(ii) The A gene}

The segregation about the point of discontinuity at 1 on the sterile base scale is controlled by the alleles of a major genetic factor which we have denoted the $A$ gene. Plants carrying this factor have a sterile base score of $\leqslant 1$, i.e. the first flower may be defective but all flowers from the second onward are normal. $S t_{2}$ is the only speltoid line with defects in flowers beyond the first, and hence is our only source of the $a$ allele. The seven vulgare varieties tested all carry $A$.

All $\mathrm{F}_{1} \mathrm{~s}$ in the crosses between $S t_{2}$ and other speltoids have defects only in the first flower (fig. 6). In the $\mathrm{F}_{2}$ s there is a $3: 1$ ratio for "first flower defects only" to " second flower defects".

No statistically significant deviation from this ratio has occurred in the $\mathrm{F}_{2} \mathrm{~S}$ of crosses of $S t_{2}$ with different speltoids and in segregating families in the crosses $\left(S t_{\mathrm{F}} \times S t_{2}\right)$ and $\left(S t_{1} \times S t_{2}\right)$ from the $\mathrm{F}_{3}$ onward. Nor has any heterogeneity been detected in replicates within a single cross, between the different crosses or between years when the segregations of different crosses were pooled. The same goodness of fit was characteristic of the speltoid $F_{2}$ fractions of the crosses of $S t_{2}$ with $Y_{\text {eoman }}$ and Victor. A representative sample of these data is presented in tables 4 and 5. The expression of the $A$ allele is thus independent of polygenic background and of a wide range of growth conditions in the field.

In all cases, the segregation has been determined in relation to the sterile 


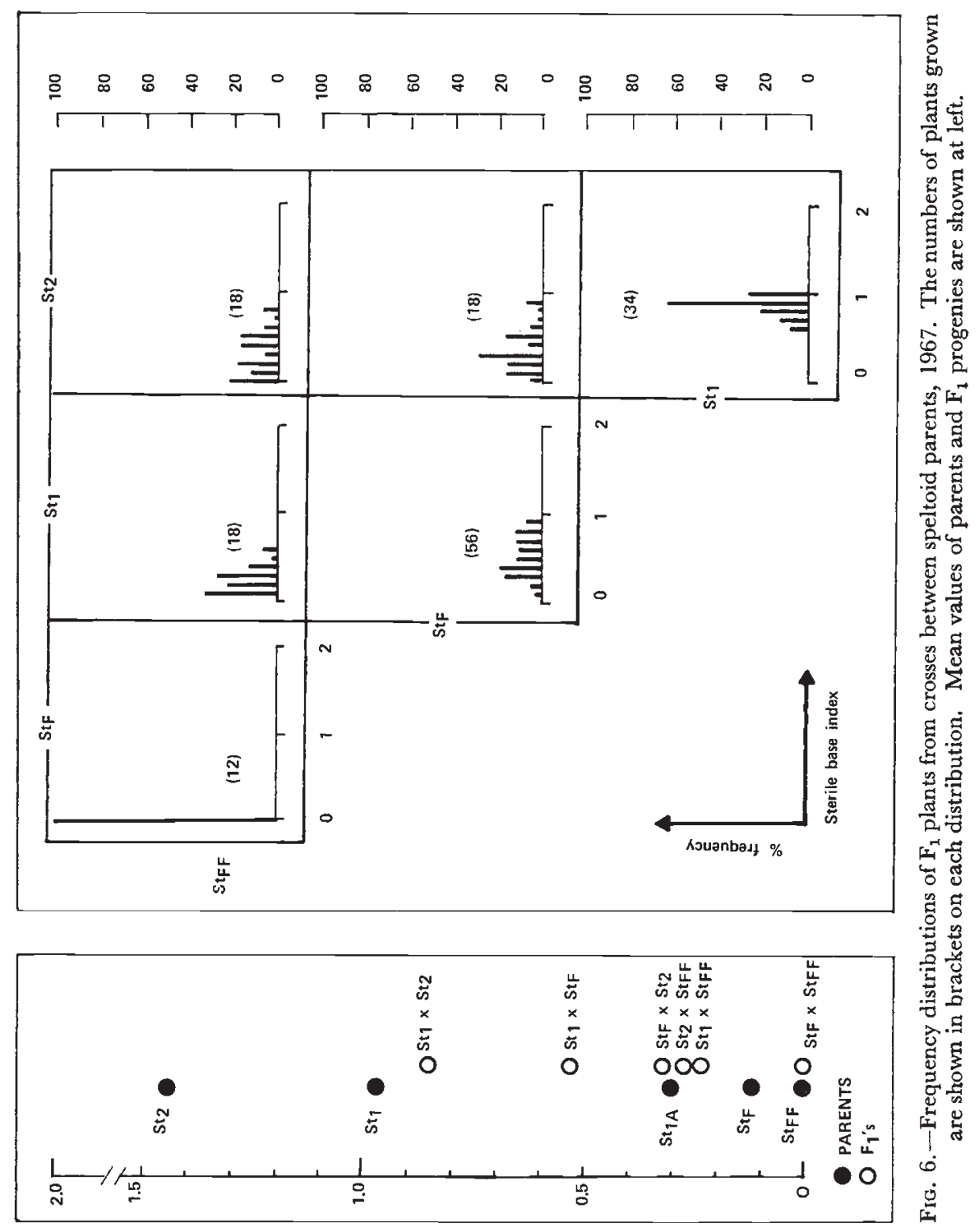


TABLE 4

Segregation numbers and deviation and heterogeneity chi-squares in $F_{2}$ speltoids segregating for the gene, A $\dagger$

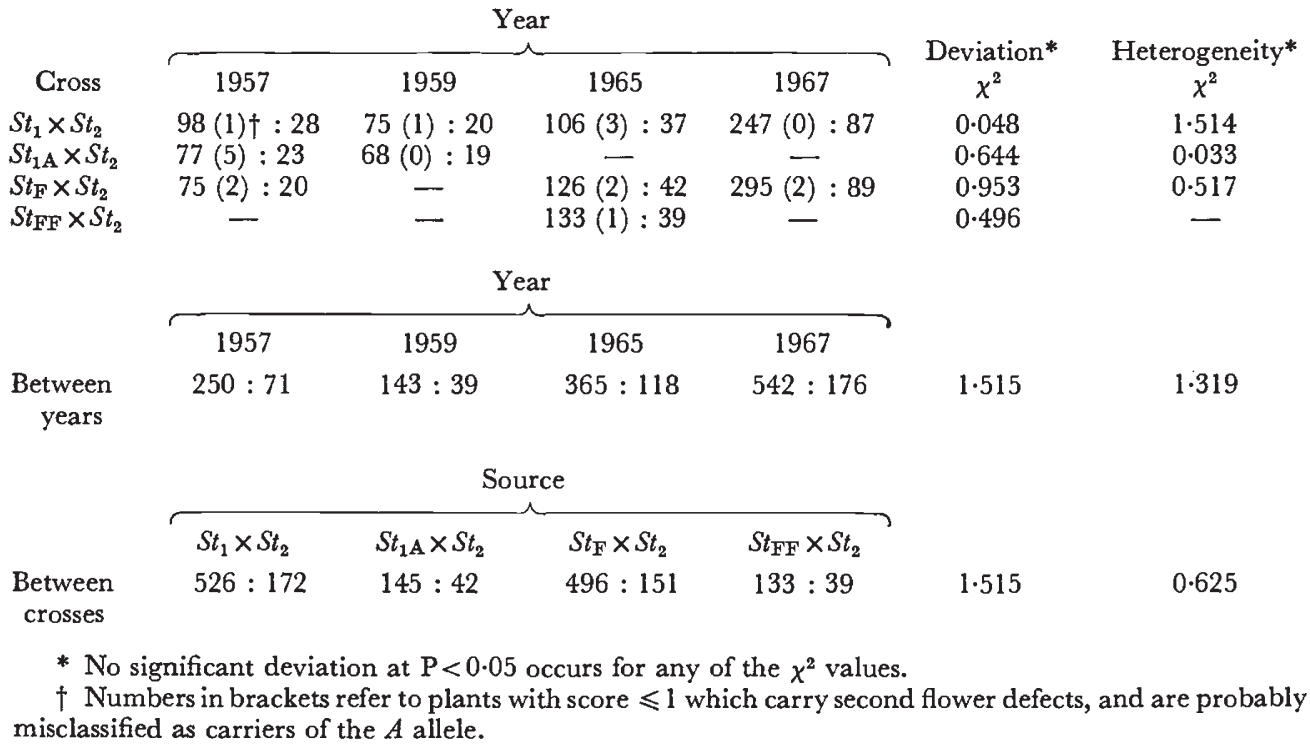

\section{TABLE 5}

Segregation numbers and deviation and heterogeneity chi-squares in $F_{4}$ speltoid progenies segregating for the gene, $\mathrm{A}$ $S t_{1} \times S t_{2}$

\begin{tabular}{|c|c|c|c|c|}
\hline Data pooled & Segregations for & \multicolumn{3}{|c|}{ Heterogeneity $\chi^{2 *}$} \\
\hline for & about point 1 & Deviation $\chi^{2 *}$ & & d.f. \\
\hline 1960 & $204: 68$ & 0.000 & 0.4844 & 4 \\
\hline 1961 & $686: 208$ & $1 \cdot 433$ & $1 \cdot 941$ & 3 \\
\hline \multicolumn{5}{|l|}{$S t_{\mathrm{F}} \times S t_{2}$} \\
\hline 1960 & $183: 62$ & $0 \cdot 012$ & $2 \cdot 687$ & 2 \\
\hline 1961 & $725: 249$ & $0 \cdot 166$ & 5.952 & 2 \\
\hline
\end{tabular}

Data pooled by year and cross

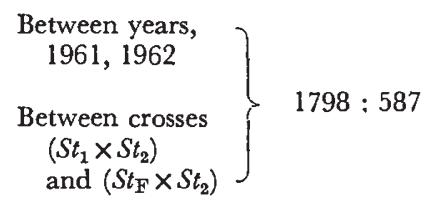

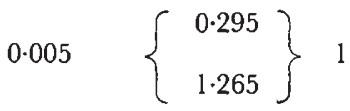

* No significant deviation at $\mathrm{P}<0.05$ occurs for any of the $\chi^{2}$ values shown.

base score and not with respect to the incidence of second flower defects. This is relevant to the $\mathrm{F}_{2}$ plants-already referred to-which have second flower defects in spite of a score $\leqslant 1$. These are shown in brackets in table 4 . Their inclusion in either class does not significantly affect the $3: 1$ segregation ratios. We have not yet determined which of the alternative alleles 
these plants carry; but since plants of this type can be obtained in progenies of $a a$ plants selected for low score this suggests that they are $a a$. There may, however, be some other factor which results in the breakdown of the normal control of spikelet differentiation.

\section{(iii) Dosage effect of Gene A}

$\mathrm{F}_{2}$ plants with a sterile base score between 0 and 1 in $S t_{2}$ crosses can be expected to be either homozygous or heterozygous for $A$. The question arises: to what extent does the dosage of the $A$ allele affect the incidence of first flower sterility?

Information on this point comes from a comparison of $A A$ and $A a$ plants in a sample from the same $1957 \mathrm{~F}_{2}$ population. When plants with a score $\leqslant 1$ were classified as $A A$ or $A a$ by $\mathrm{F}_{3}$ progeny tests, it was found that the

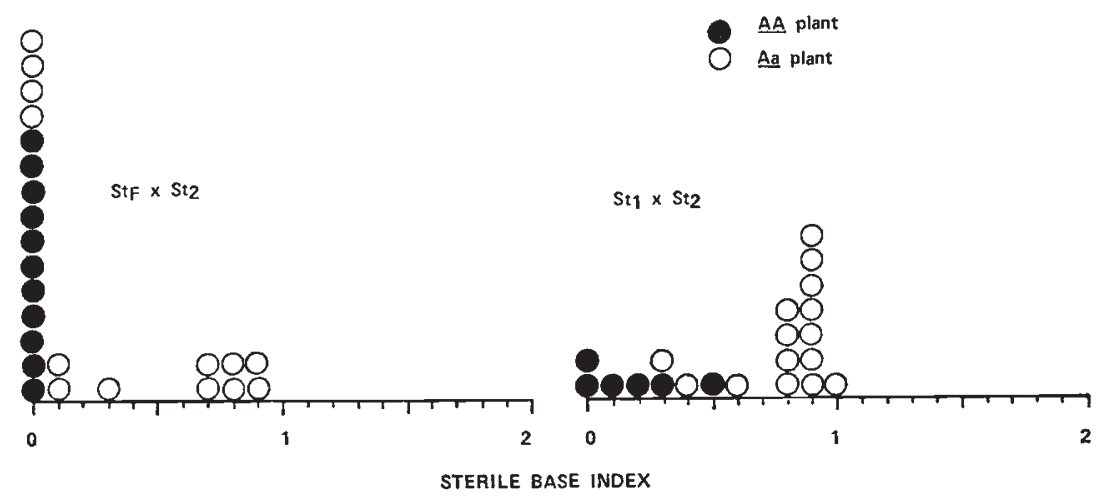

FIG. 7.-The distribution of randomly selected $A A$ and $A a$ plants from the $\left(S t_{\mathrm{F}} \times S t_{2}\right)$ and $\left(S t_{1} \times S t_{2}\right) \mathrm{F}_{2} \mathrm{~s}, 1957$.

heterozygotes were more base sterile than the homozygotes and that there was very little overlap between the two groups irrespective of the location of the sample as a whole in the 0-1 range (fig. 7).

In the $\mathrm{F}_{2}\left(S t_{\mathrm{F}} \times S t_{2}\right)$, all $A A$ plants were at 0 , and the $A a$ plants had a mean of 0.4 . Similarly, in the $\mathrm{F}_{2}\left(S t_{1} \times S t_{2}\right)$ the mean of the $A A$ plants was 0.2 , that of the $A a$ plants $0 \cdot 8$. It is clear that the $A$ allele has a dosage effect on the basal fertility of the first flower.

The relatively high basal fertility of the $A A$ plants from the $\mathrm{F}_{2} \mathrm{~s}$ of both of these $S t_{2}$ crosses contrasts with the $\mathrm{F}_{2} \mathrm{~s}$ of a number of crosses between $A A$ parents conferring high basal fertility $\left(S t_{\mathrm{F}}\right.$, Victor) and high basal sterility $\left(S t_{1}, Y_{e o m a n}\right)$, in which the distributions extend all the way from 0 to 1 (fig. 3). The explanation for the difference between these and the $S t_{2}$ crosses must be in the constitution of $S t_{2}$ itself, or, more specifically, in the interaction of alleles contributed by $S t_{2}$ and the $A$ gene. This accounts for the very great number of plants in the $\left(S t_{1} \times S t_{2}\right) \mathrm{F}_{2} \mathrm{~s}$ which are more base fertile than either of the parents (fig. 4).

\section{(iv) Analysis of the continuous variation}

The evidence so far presented suggests that although the $A$ gene has a major role in the determination of basal fertility, there are other genetic elements with which it interacts. In view of the distinctive nature of the 
distribution in the presence or absence of $A$, the two ranges of variation, 0-1 and $>1$, are discussed separately.

The $0-1$ range. Though some of the parent lines in this range overlap, their means and variances indicate characteristic differences which are consistent over the many experiments in which they have been observed. The means of the $\mathrm{F}_{1} \mathrm{~s}$ between the speltoids (fig. 6 ) tend to be highly correlated with the order of the means of the parent lines. The high mean value for the $\left(S t_{1} \times S t_{2}\right) A a$ hybrids contrasts with the low scores of $A A \mathrm{~F}_{2}$ plants from this cross (fig. 7), and confirms that an increased dosage of $A$ makes the head more base fertile. The $\mathrm{F}_{2} \mathrm{~s}$ show similar trends (figs. 3 and 4 ). In the 0-1 range, $S t_{\mathrm{FF}}, S t_{\mathrm{F}}$ and $S t_{1}$ tend to increase the sterility of distributions in comparable crosses in the order to be expected from their parental values. A comparison of comparable $\mathrm{F}_{2}$ s from Victor and reoman consistently reflect the more fertile background of Victor. This is not surprising in the case of the speltoids since, with the exception of $S t_{1 \mathrm{~A}}$, these lines were obtained by selection for increased or decreased sterility in populations directly or indirectly derived from $S t_{1}$. The results confirm the supposition that the parents differ by sets of genes which are largely additive in their effect.

A different line of evidence for the existence of genetic factors controlling the variation in the $0-1$ range comes from selected $F_{4}$ to $F_{6}$ progenies from the cross $\left(S t_{\mathrm{F}} \times Y_{\text {eoman }}\right)$. An attempt was made to stabilise progenies between points 0 and 1 . Representative plants from a range of $F_{4}$ families were grown on in $F_{5}$, and this procedure was repeated from $F_{5}$ to $F_{6}$. The grand means of $F_{5}$ and $F_{6}$ offspring progenies are plotted against the means of their respective parent progenies in fig. 8. It can be seen that the relationship between generations, as shown in this figure, is non-linear, departures from linearity being most marked in the middle of the range, though at points 0 and 1 fixation is practically complete across the three generations. In addition, the departures from linearity have been in opposite directions in different years, the $\mathrm{F}_{5} \mathrm{~s}$ being more sterile and the $\mathrm{F}_{6} \mathrm{~s}$ more fertile than their respective parents. These two features are a reflection of the proneness to environmental instability of populations from the middle of the 0-1 range. However, when only the ranks of the means of progenies are taken into account, the ranks of both the $\mathrm{F}_{4}$ and $\mathrm{F}_{5}$ parent progenies show a highly significant correlation with those of their offspring. A rank correlation which is significant at the 5 per cent. level also occurs when progenies with a mean value $>0.85$ and $<0.15$ are ignored. These results support the view that genetic factors contribute to variation across the whole range from 0 to 1 .

The $>1$ range. Insight into the nature of the genetic controls operating in this range was obtained from lines grown from a random sample of aa plants from the $\mathrm{F}_{2} \mathrm{~s}$ of the crosses $\left(S t_{2} \times S t_{\mathrm{F}}\right)$ and $\left(S t_{2} \times S t_{1}\right)$. These were grown as far as the $F_{4}$ without selection. Thereafter selections were made for high and low sterile lines and to stabilise lines at intermediate values.

The responses of the two crosses, surprisingly, in view of the considerably greater basal fertility of the $\left(S t_{\mathrm{F}} \times S t_{2}\right)$ cross in the $0-1$ range, were very similar here in the clear segregation of lines in the $\mathrm{F}_{3}$ and $\mathrm{F}_{4}$, and in their ready response to selection for high and low basal sterility in later generations. A comparison of the $a a$ segments of two $\mathrm{F}_{2} \mathrm{~s}$ grown in adjacent rows in 1967 (table 6) showed the $\left(S t_{\mathrm{F}} \times S t_{2}\right)$ cross to be more base sterile. Whatever 
the precise relation of the contribution of $S t_{\mathrm{F}}$ and $S t_{1}$ in the $>1$ range, the differences effective between 0 and 1 do not appear here.

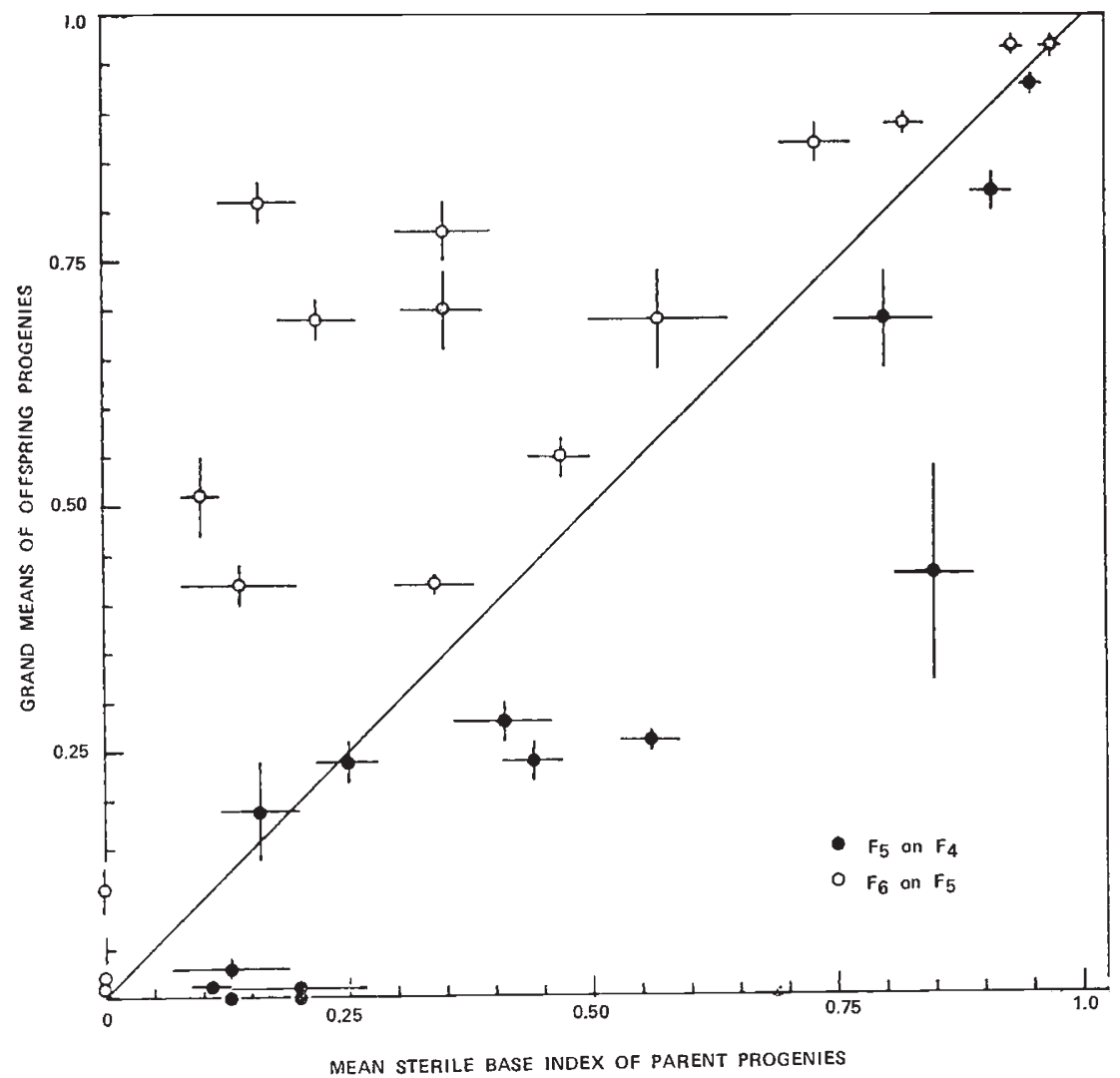

FIG. 8. - The grand mean sterile base indices of offspring $F_{5}$ (closed circles) and $F_{6}$ progenies (open circles) are plotted against the mean values of the progenies from which their parents were selected. The standard errors of offspring and parent progenies are given.

The relationship of $\mathrm{F}_{3}$ and $\mathrm{F}_{4}$ in the two crosses are shown in figs. $9 a$ and $9 b$, where the means of $\mathrm{F}_{4}$ progenies are plotted against the scores of their $\mathbf{F}_{\mathbf{3}}$ parents. The prominent features are the linearity of the relationship, and

TABLE 6

Frequency distribution of plants $>1$ in the $F_{2}$ s of two $\mathrm{St}_{2}$ crosses, 1967

Numbers of plants in each class are given

$\begin{array}{cccccc}\text { Sterile base score } & 1 \cdot 0-1 \cdot 5 & 1 \cdot 5-2 \cdot 0 & 2 \cdot 0-2 \cdot 5 & >2 \cdot 5 & \text { Total } \\ S t_{1} \times S t_{2} & 11 & 56 & 12 & 8 & 87 \\ S t_{\mathrm{F}} \times S t_{2} & 12 & 37 & 22 & 18 & 89 \\ S t_{2} \text { parent } & 19 & 9 & 0 & 0 & 28\end{array}$

the highly significant nature of the regressions, indicating that there is a considerable genetic component affecting basal fertility in this part of the scale. 


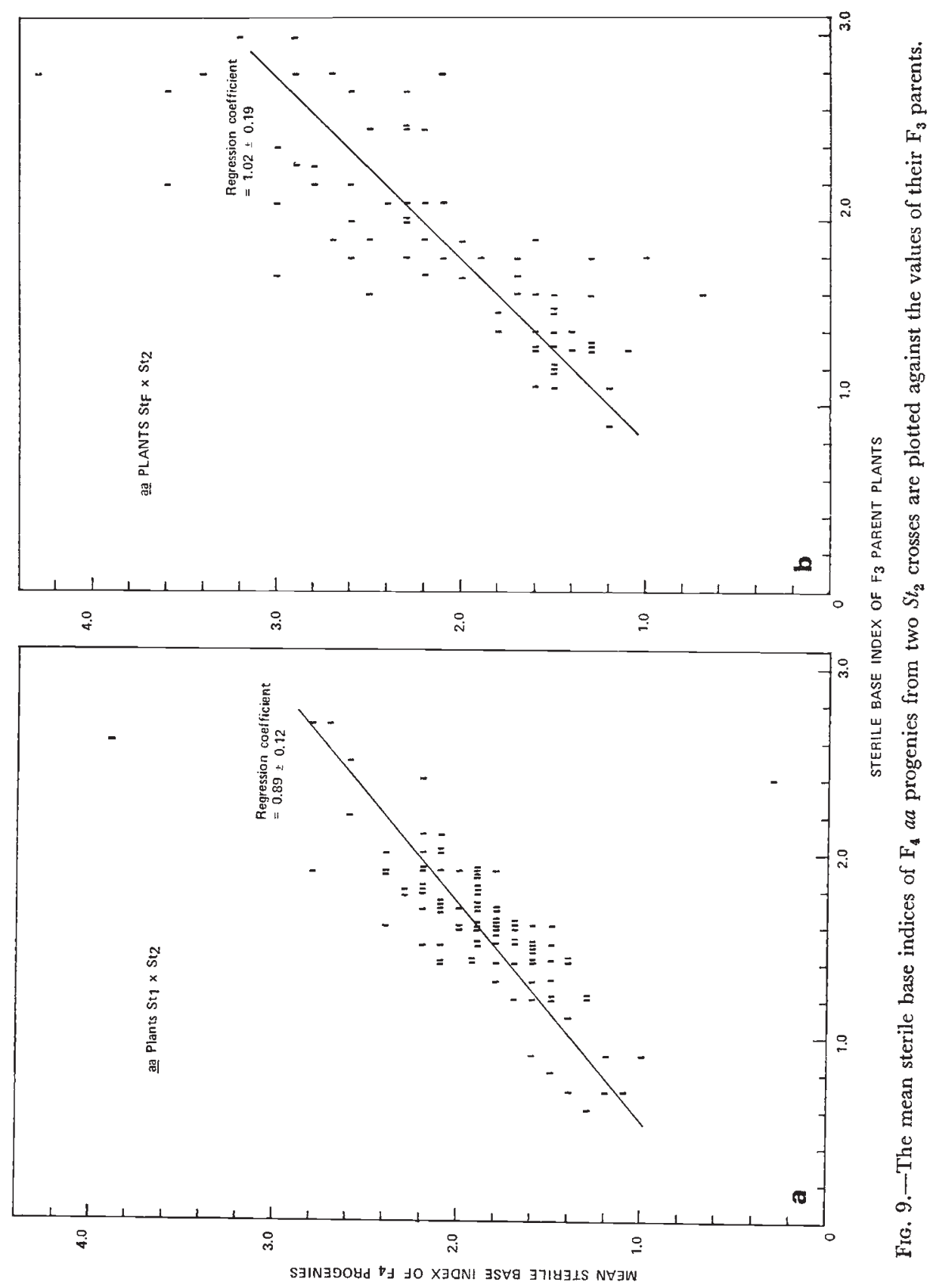


The presence of genetic variance in the $\mathrm{F}_{4} \mathrm{~s}$ derived from these plants is clear from the ready response to selection for high and low sterile lines. Lines with mean values as high as $7-8$ and as low as 0.7 were obtained by the $\mathrm{F}_{6}$ and $\mathrm{F}_{7}$ generations.

\section{Discussion}

Stability in the expression of basal fertility in our stocks approaches completeness at only two values of the sterile base index, 0 and 1 , and it occurs only in lines where the spikelets within a head are uniformly affected. In vulgare wheats, such as Victor and Yeoman, the spikelets are uniformly base fertile, but the same applies also to a speltoid line such as $S t_{\mathrm{FF}}$ derived from the cross $\left(S t_{\mathrm{F}} \times S t_{2}\right)$ and there has been no difficulty in selecting for very stable lines in a large number of our crosses. Stability at this point, therefore, is independent of the vulgare syndrome. At a sterile base index of 1 highly buffered speltoid lines, similar to $S t_{1}$, can also be selected. In these lines, all spikelets tend to carry a single defective flower, with the exception of the apical spikelet which is a good deal more variable than the rest.

Three genetic systems affecting the development of basal floral primordia have been found in vulgare and its speltoid derivatives. They are (1) the vulgare factor, $Q ;(2)$ the $A$ gene; and (3) a polygenic system which modifies either allele at the $A$ locus.

$Q$ is inherited as a single dominant gene and its effect on basal fertility is independent of variability in the other components of the genetic system. Thus the normal development of $Q$-bearing vulgares is buffered against the expression of cryptic genetic variance for basal fertility which is exposed by the removal of $Q$ in suitable crosses. Data for reoman illustrate this point. This Q-bearing vulgare indubitably carries the $A$ allele, as does the mutant $S t_{1}$ which is derived from it. But the vulgare-type segregants in the cross $\left(Y_{\text {eoman }} \times S t_{2}\right)$, one-quarter of which must be $a a$, are all normal. Nor is Yeoman affected by its "background" which must be close to that of $S t_{1}$. Confirmation comes from the distribution of speltoids in the $\mathrm{F}_{2}\left(Y_{\text {eoman }} \times S t_{1}\right)$ which is similar to that of $S t_{1}$.

In its effect on basal fertility at the second flower level, the effect of the $A$ gene is analogous in a number of ways to that of the $Q$ factor on the 1 st flower. With either a single or double dosage of the $A$ gene, the second floret of all spikelets is fully fertile. The fact that this has been the case in all $A$-bearing stocks over a large number of years under field conditions, regardless of the polygenic background of the stocks, indicates the strong effect of this gene. This may also be inferred from the very close fit of the $3: 1$ segregation of the $A: a$ alleles of this gene under similar conditions. As with $Q$, speltoids carrying $A$ are buffered against the expression of underlying genetic variance for a base sterile score $>1$.

There are also several important differences. Unlike $Q, A$ has no effect, as far as we know, on other characters besides basal fertility. The presence of $A$ is compatible with a range of variation from full fertility to complete failure of the first flower depending on the dosage of $A$, the polygenic background and, presumably, their interaction. In combination with selected background genes, the presence of $A$ results in normal buffered basal fertility, which is as complete as in any vulgare.

Variation of the background polygenic system provides the basis of selection across the whole range of our scale. The marked response to 
selection in the presence of either $A$ or $a$, and also the extensive correlation of $F_{1}$ and $F_{2}$ means in the $0-1$ range with parental values, suggest that this background includes genes of major additive effect on our scale. The absence of phenotypic discontinuities, such as occur at point 1, prevents their individual analysis.

Perhaps the most striking difference between $A$ and $a$ is found in comparisons of $a a$ distributions in the $\mathrm{F}_{2} \mathrm{~s}$ of $S t_{2}$ with $S t_{\mathrm{F}}$, and $S t_{1}$. $S t_{\mathrm{F}}$ and $S t_{1}$ are identical for $A$, but differ widely in their genetic background. This is clearly exhibited by the distribution of the two populations in the 0-1 range. But beyond point 1 , the two $F_{2}$ populations are similar, with an indication of higher sterility in the cross with the more fertile parent. The response to selection for increased basal sterility from the $F_{3}$ onwards was similar in both crosses. This contrast in the effect of the genetic background upon the $\leqslant 1$ and $>1$ ranges suggests distinct genetic systems at the two developmental levels.

The coexistence of distinct genetic components capable of exerting a strong effect on basal fertility may best be interpreted in terms of the polyploid nature of wheat. They may represent alternative genetic pathways, derived from ancestral diploid species. The evolution of the system, however, is not the subject of this report. But, in principle, it has been shown how alternative genetic systems not expressed under normal conditions may produce the same invariant phenotype as is achieved in the presence of $Q$. This genetic system may also be used to provide an alternative canalised end-state of development with what amounts to three glumes. This is in accordance with the developmental homology of glume and lemma (Barnard, $1955 a)$.

What functions can be ascribed to genes affecting basal fertility? An essential feature of Waddington's concept of canalisation is that the invariance of a developmental character may be understood only in terms of the interaction of two distinct kinds of processes. These are determined by two sorts of genes, those in which alterations tend to produce variation in the phenotype, and canalisation or control genes tending to protect the organism against phenotypic variability.

A number of observations suggest that the gene systems we have identified are of the former kind and do not act as components of control mechanisms of the kind envisaged in Waddington's concept. The canalisation of basal fertility can be obtained independently of $Q$, since stable speltoid lines can be selected by using variation of the polygenic background in the presence of $A$. In the 0-1 range, control mechanisms seem to remain intact even though the $Q$ factor has been deleted. The evidence for this is the ease of selecting towards canalised speltoid phenotypes. The difference between a relatively poorly canalised line like $S t_{\mathrm{F}}$ and a completely canalised one like $S t_{\mathrm{FF}}$ is due to variation in genes which are largely additive in their effect and is unlikely to be due to differences in the control genes they carry. Since the effect of a change from a single to a double dosage of the $A$ allele is to decrease the level of basal sterility in a head, it would be difficult to ascribe a control function to this gene. Indeed, the dosage effect of $A$ is analogous to that which can be obtained by means of the polygenic system.

An assessment of the function of $Q$ is problematical, because of the difficulty in inducing variation in $Q$-carrying stocks. The observations of Wright (1958) on compactoid mutants with four $Q$-bearing $5 \mathrm{~A}$ chromosomes, 
however, are relevant. These plants have rudimentary and sometimes functional flowers in one or both of the normally empty glumes at the base of spikelets. This indicates the strength of the canalisation of basal fertility in normal vulgare wheats and a dosage effect of the $Q$ factor which in principle is analogous to that of the $A$ gene. We have observed a similar addition of flowers in our vulgare lines, Victor and Yeoman, when they are subjected to high temperature and short days during a sensitive period in their development. Though the response is only minimal, the fact that it was more pronounced in Victor, in which the polygenic background is more fertile than in Yeoman, suggests that their polygenic systems may reinforce the action of $Q$ and that these two systems may affect a single developmental process. The tendency of the upper spikelets to accumulate extra flowers in these lines is analogous to the response of most of our sterile base stocks where a general increase in basal fertility is brought about by the accumulation of fertile base florets from the tip of the head downwards. From this evidence it seems that the three genetic systems are analogous in their function and that they are not canalisation genes in Waddington's sense.

Waddington $(1957,1962)$ has suggested that a feedback system is the essential component which keeps a developmental pathway moving towards an invariant end state. Rendel (1967) has elaborated a model in which the product of control genes can interact with a feedback product to repress the action of genes which tend to increase scutellar bristle number in D. melanogaster. While recognising the need for an interaction of at least two processes to account for the controlled expression of basal fertility, we believe that this can be done without involving feedback mechanisms. The following model is an extension of that developed by Fraser (1950) to account for the siting of zones of floral competence along the axis of individual spikelets in sterile base lines.

In this model we assume the existence of a temporal sequence of sensitivity of floral primordia to an "activator" substance which triggers their differentiation. The buffered and unbuffered states would be the products of the interaction of two variables: one, the time of arrival of the " activator "; the other, the competence of primordia to respond.

On this assumption, there would be two components of the temporal sequence of sensitivity within a spike. The primordia of a spikelet would become competent to differentiate sequentially from the base towards the tip. A temporal gradient of sensitivity could also be expected along the axis of the spike. The simplest head gradient would, as in the case of the spikelet, be from the base towards the tip, though one could expect to find random and possibly some genetic modification in this pattern. The head gradient envisaged here need not be correlated with that of the rates of maturation of parts of the spike after floral differentiation has occurred.

One cannot specify the nature of the "activator" beyond assuming that it is a photosynthetic component originating outside the spike. The products of the $Q, A$ and polygenic systems determine the velocity of " activator" formation and thus the timing and the rate of its arrival in the spike. One assumes that these are subject to random disturbances and, conceivably, shifts of a directional nature as the result of specific environmental effects.

An interpretation of the buffered states at 0 and $l$ in terms of this model is straightforward. The functioning of $Q$ causes a sufficient concentration of 
"activator" in the spike to promote the differentiation of first floret primordia as they become competent. First flowers in this case are all fertile. In speltoids, $A$ produces the same effect in relation to the primordia of the second florets. Random fluctuations in the rate of the formation of the products of $Q$ and $A$ would not affect the stability of these developmental characteristics. In unbuffered $A$-bearing speltoids, however, the development of the first flower would be sensitive to fluctuations in the arrival of the $A$ product in the spike. In the absence of $Q$, the products of polygenic factors may supplement those of $A$, resulting in speltoid lines as highly buffered at point 0 as vulgares.

On this model one must assume a high degree of coordination of the sensitive periods of first flower primordia and, further, their distinctness from those of second flower (and possibly upper glume) primordia. If; however, a polarity of competence along the head exists, an overlap of sensitive periods at different spikelet levels is not precluded.

The main contribution to changes in the average sterility carried by a spike would be expected to come from variation in the determinants of the rate of formation of the " activator". This has apparently been the case in our data. However, variation in the genetic determinants of temporal gradients of sensitivity could also be expected. This seems to have occurred in the aa lines selected for high basal fertility from plants with a small number of second flower defects. Plants from these lines carry a range of defective first and second florets at the base of the spike to completely base fertile spikelets towards the apex in spite of their low average basal sterility. On this model, one assumes a loss of co-ordination in the timing of first flower competence along the spike, which creates the opportunity to select for an increase in the fertility of the upper spikelets without a comparable decrease in the sterility of spikelets at the base of the spike. This has no doubt played a major role in the selection of highly base fertile a lines.

\section{Summary}

1. Whereas fully competent flowers form at the base of all spikelets of a head in normal vulgare wheat, the basal florets of some speltoid mutants are defective. The displacement of floral development towards the apex of a spikelet in these plants has been measured by means of a sterile base index, which expresses the mean number of defective florets carried by the spikelets of a head.

2. Selection has resulted in the formation of speltoid lines with mean indices ranging from 0 to 9 . With the exception of lines at 0 and 1 on the index, all are subject to considerable environmental variation; at these points it is possible to select for speltoid lines which are, or tend to be, as fully buffered for the development of basal flowers as vulgare wheats.

3. Three genetic components have been analysed for their effect on the development of basal flowers: (1) a genetic element associated with the vulgare factor, $Q$; (2) the $A$ gene and its recessive allele, $a$; and (3) a polygenic system which interacts with either allele of the $A$ gene.

4. In the presence of $Q$, plants are completely base fertile and are buffered against the expression of cryptic genetic variance in basal fertility, as well as variability due to environmental factors.

5. The effect of $A$ on the fertility of the second flower is analogous to that 
of $Q$ on the fertility of the first. But a change from a single to a double dose of the $A$ allele increases the incidence of the first flower fertility.

6. The presence of two doses of $a$ leads to defects in second flowers and permits the expression of variation in the polygenic system which may not otherwise be apparent.

7. A model of the physiological mechanism underlying the expression of basal fertility is outlined.

Acknowledgments.-We are indebted to Mrs Ruth Gani for her contribution to the collection and analysis of data in the early stages of this project. We also wish to thank Miss Mary Roskams for her assistance.

\section{REFERENCES}

BARNARD, G. 1955a. Histogenesis of the inflorescence and flower of Triticum aestivum L. Aust. 7. Bot., 3, 1-20.

BARNARD, c. 1955b. Sterile base florets in Triticum. Aust. F. Bot., 3, 149-164.

DUN, R. B., AND FRASER, A. s. 1958. Selection for an invariant character-" Vibrissa Number" -in the house mouse. Nature, 181, 1018-1019.

FRANKEL, O. H., AND FRASER, A. s. 1948. Base sterile mutants in speltoid wheat. Heredity, 2, 391-397.

FRASER, A. s. 1950. Basal sterility in wheat. Nature, 165, 653.

HUSKINS, C. L. 1946. Fatuoid, speltoid and related mutations of oats and wheat. Botanical Review, 12, 457-514.

Lerner, 1. M. 1954. Genetic Homeostasis. Oliver and Boyd, Edinburgh.

MATHER, K. 1953. The genetical structure of populations. Symp. Soc. Expt. Biol., 7, 66-95. RENDEL, J. M. 1959. Canalisation of the scute phenotype of Drosophila. Evolution, 13, 425-439.

RENDEL, J. M. 1967. Canalisation and Gene Control. Logos Press, London.

WADDington, C. H. 1953. Genetic assimilation of an acquired character. Evolution, 7, 118-126.

Waddington, c. H. 1957. The Strategy of the Genes. Allen and Unwin Ltd., London.

waddington, c. H. 1962. New Patterns in Genetics and Development. Columbia Univ. Press, New York.

WRIGHT, G. M. 1958. Grain in the glume of wheat. Nature, 181, 1812-1813. 